\title{
Kemoterapi ve Radyoterapi Alan Hastalarda Oral Mukozit: Bir Gözden Geçirme
}

\author{
Seher ÇAKMAK*, Nesrin NURAL**
}

$\ddot{O} \mathbf{z}$

Oral mukozit, kemoterapi ve/veya radyoterapiyi takiben oral mukoza bütünlüğünün bozulmasıyla ortaya çıkmaktadır. Özellikle baş-boyun bölgesine uygulanan radyoterapi, antimetabolit ve alkilleyici kemoterapi ajanları oral mukozit sıklığında ve şiddetinde artışa neden olmaktadır. Oral mukozit gelişen hastalarda ağız/boğazda ağrı, enfeksiyon ve kanama gibi ciddi komplikasyonlar ortaya çıkmaktadır. Ayrıca günlük yaşam aktivitelerinde bozulma, sıvı, besin ve analjezi desteği, hastanede yatış süresinin uzaması ve tedavi maliyetinde artış gibi klinik ve ekonomik sonuçları olabilmektedir. Oral mukozitin önlenmesi/tedavisinde farmakolojik ve farmakolojik olmayan birçok ajan kullanılmaktadır. Bu derlemede oral mukozitin tanımı, epidemiyolojisi, gelişme mekanizması, etiyolojisi/risk faktörleri, klinik/ekonomik sonuçları, değerlendirilmesi, önlenmesi/tedavisi ve hemşirenin rolü tartış1lacaktır.

Anahtar Sözcükler: Hematopoetik Kök Hücre Nakli, Kemoterapi, Oral Mukozit, Radyoterapi.

\section{Abstract}

\section{Oral Mucositis in Patients Undergoing Chemotherapy and Radiotherapy: A Review}

Oral mucositis is caused by disruption of oral mucosal integrity following chemotherapy and / or radiotherapy. Especially head and neck radiotherapy, antimetabolite and alkylating chemotherapy agents cause an increase the frequency and severity of oral mucositis. In patients with oral mucositis emerges serious complications such as pain in the mouth / throat, infection and bleeding. It may also have clinical and economic consequences such as deterioration in daily living activities, fluid, nutrient and analgesia support, prolonged hospital stay and increased treatment cost. Many pharmacological and non-pharmacological agents are used in the prevention / treatment of oral mucositis. In this review, the definition, epidemiology, developmental mechanism, etiology / risk factors, clinical / economic outcomes, evaluation, prevention/treatment of oral mucositis and the role of nurse will be discussed.

Key Words: Hematopoietic Stem Cell Transplant, Chemotherapy, Oral Mucositis, Radiotherapy.

Geliş tarihi: 17.10.2019 Kabul tarihi: 23.05.2020

$\mathrm{O}$ ral mukozit (OM), kanser tedavisinin yaygın bir toksisitesidir. Bu komplikasyon kemoterapi (KT), radyoterapi (RT) ve hematopoetik kök hücre naklinin (HKHN) bir sonucu olarak ortaya çıkmaktadır $(1,2)$. Klinik bulgular hafif ağrı ve eritemden ağrılı şiddetli ülserasyonlara kadar değişmektedir. Oral mukozitin gelişiminde rol oynayan birçok faktör bulunmaktadır. Şiddetli $\mathrm{OM}$ yeme, yutma ve konuşma güçlüklerine neden olarak hastanın günlük işlevlerini ve yaşam kalitesini bozmaktadır $(3,4)$. Bu derlemede OM'nin tanımı, epidemiyolojisi, gelişme mekanizması, etiyolojisi/risk faktörleri, klinik/ekonomik sonuçları, değerlendirilmesi, önlenmesi/tedavisi ve hemşirenin rolü tartışılacaktır.

\section{Oral Mukozitin Tanımı}

\section{Gelişme}

Oral mukozit, KT ve/veya RT'nin bir sonucu olarak oral mukozada meydana gelen ülseratif ve inflamatuvar değiş̧iklikler ile karakterizedir $(1,5)$.

\section{Oral Mukozitin Epidemiyolojisi}

OM, kanser tedavisinin yaygın ve zayıflatıcı toksisitelerinden biridir. Yüksek doz kemoterapi (YDKT) alan hastalarda OM insidansı standart doz KT alan hastalara göre daha yüksektir. Standart doz KT alan hastaların \%12-51'inde (6-8), HKHN için YDKT alan hastaların \%58-99'unda $(2,9,10)$ OM geliştiği bildirilmektedir. Ağız, orofarenks ve nazofarenks kanserleri için baş-boyun bölgesinden RT alan hastaların ise \%80-100'ünde $(1,11)$ ortaya çıkmaktadır.

\section{Oral Mukozitin Gelişsme Mekanizmast}

Oral mukozit, KT alan hastalarda sıklıkla yumuşak damak, yanak ve dudakların hareketli keratinsiz mukozası, dilin ventral yüzeyi ve ağız tabanı, daha az sıklıkta diş eti, dilin dorsal yüzeyi ve sert damakta gelişmektedir $(12,13)$. Radyoterapi alan hastalarda ise 1şın verilen bölgeye göre değiş̧mektedir (1). Kemoterapiye bağlı OM ilaç infüzyonundan yaklaşık 3-5 gün sonra başlamakta, 7-14. günlerde şiddeti artmakta ve 5-10 gün içinde iyileşmektedir (14) . Radyoterapiye bağlı OM, RT'nin başlangıcından itibaren 2 hafta içinde veya sonrasında gelişmekte ve sekiz haftaya kadar devam etmektedir (15). YDKT alan ve HKHN yapılan hastalarda da OM, nakilin 1-14. günlerinde ortaya çıkmakta ve 2-40 gün sürmektedir (16).

Kemoterapi ve/veya RT doğrudan ve dolaylı yollardan hücre hasarına neden olmaktadır. OM oluşumunda beş aşamalı karmaşık biyolojik olaylar zinciri gerçekleşmektedir. Bunlar $(1,17)$ :

Başlatma: KT ve/veya RT, epitel, vasküler endotel, fibroblastlar ve doku makrofajlarından reaktif oksijen türlerinin (ROT) üretimine yol açmaktadır. ROT'lar DNA, lipidler, konnektif doku ve diğer biyomoleküllere zarar vermektedir. KT seramid sentezini, RT'de nükleer faktör-kappa B'yi (NF-kB) uyarmaktadır.

Birincil hasar yanıtı: Birincil hasara yanıt olarak DNA hasarı ve ROT'lar; (1) fibronektin parçalanmasına, (2) gen ekspresyonunu uyaran NF-kB aktivasyonuna ve proinflamatuvar sitokinlerin salınımına (TNF- $\alpha$, interlökin (IL) -1 $\beta$ ve IL-6) ve (3) sfingomyelinaz ve seramid sentezinden dolayı seramid yoluna neden olmaktadır. Serbest kalan sitokinler epitel, endotel ve bağ dokusunda doku hasarına ve apoptozise yol açmaktadır. Mukozada incelme ve eritemli alanlar gelişmektedir.

\footnotetext{
* Araş. Gör., Karadeniz Teknik Üniversitesi Sağlık Bilimleri Fakültesi, Hemşirelik Bölümü, İç Hastalıkları Hemşireliği Anabilim Dalı, Trabzon, E-mail: sehercakmak@ktu.edu.tr, seher.seher61@gmail.com ORCID: https://orcid.org/0000-0003-4684-8333. ** Prof. Dr., Karadeniz Teknik Üniversitesi Sağlık Bilimleri Fakültesi, Hemşirelik Bölümü, İç Hastalıkları Hemşireliği Anabilim Dalı, Trabzon, E-mail: nnural@ktu.edu.tr, ORCID: https://orcid.org/0000-0003-2100-7386.
} 
Sinyal İletimi ve Amplifikasyon: Birincil hasar yanıtı sırasında üretilen proteinlerin çoğu, pozitif geri besleme döngüleri yoluyla ek yaralanmayı uyarmaktadır. Pro-inflamatuvar sitokin TNF- $\alpha$, NF- $\kappa B$, sfingomiyelinaz ve TNF reseptör familyasını aktive etmektedir. Bu geri besleme döngüleri, başlangıçtaki biyolojik sinyalleri arttırarak ve güçlendirerek ilk yaralanmanın tepkisini büyütmektedir. Bu geri besleme döngüleri sadece doku hasarını arttırmakla kalmaz, aynı zamanda KT veya RT verildikten sonraki günler boyunca sinyaller vermeye devam ederek hasarı uzatmaktadır.

Ülserasyon: Bu aşama, mukozal bütünlüğün bozulduğu aşamadır. Epitel kaybı, bazal membranda bozulmaya, ülser psödomembran oluşumuna ve inflamatuvar eksüdaya yol açmaktadır. Ülserasyon aşaması çok ağrılıdır, çünkü lamina propriadaki sinir uçlarını örten koruyucu bariyer kaybolmuştur. Ortaya çıkan mikrokoagülasyon ve nötropenik durum, ikincil enfeksiyon üretimi ile beraber Gram-negatif bakteri ve maya kolonizasyonunu kolaylaştırmaktadır. Bakteriyel ekzotoksinler, daha fazla IL-1 $\beta$, TNF- $\alpha$ ve nitrik oksit salınımı ile mononükleer patlamayı indükleyerek inflamatuvar reaksiyonu şiddetlendirmektedir.

İyileşme: Siklooksijenaz-2 (COX-2) aktivasyonu yeni anjiyogenezisi desteklemektedir. Epitel hücreleri çoğalmakta ve ülseratif yarayı kapatmak için göç etmektedir. Submukoza hücreleri yenilenmektedir. Eski dokuya tam olarak benzemeyen yeni doku oluşmaktadır.

\section{Oral Mukozitin Etiyolojisi ve Risk Faktörleri}

Kişisel ve tedavi özelliklerine bağlı olarak OM görülme sıklı̆̆ı ve şiddeti değişmektedir. Oral mukozit gelişmesine ve şiddetine katkıda bulunan kişisel özellikler; daha genç ya da ileri yaşta olmak, kadın cinsiyet, ağız sağlığı hijyeninin kötü olması, akut ya da kronik periodontal hastalıklar, enfeksiyonlar, yetersiz beslenme durumu, beden kitle indeksinin düşük olması, ağız kuruluğu, tükürük bezi salgılama işlev bozukluğu, kemik iliğinin baskılanması, ciddi nötropeni, komorbid durumlar, sigara içme, alkol kullanımı ve geçirilmiş $\operatorname{OM}$ 'dir $(3,8,18,19)$. Tedaviye bağlı özellikler ise tedavinin türü, dozu ve veriliş yolu ile ilgilidir. Tedavide alkilleyici (busulfan, melfalan, siklofosfamid), antimetabolit (metotreksat, 5-fluorourasil [5-FU]), timidin sentetaz inhibitörleri (metotreksat), topoizomeraz II inhibitörleri (etoposid, irinotekan), primidin analogları (sitozin arabinozid [ARA-C]), pürin analogları (6-mercaptopürin ve 6 thioguanin) ya da antrasiklin (idarubisin, doksorubisin, daunorubisin) KT ajanlarının kullanılması, baş-boyun bölgesinden RT uygulanması ve KT'nin RT ile birlikte uygulanması OM gelişimi için yüksek riskli durumlardır (19-21). Sitotoksik ajanların bolus ve sürekli infüzyon şeklinde uygulanması ile mukozit gelişme riski artmaktadır (22). HKHN planlanan hastalara uygulanan hazırlık rejiminin tipi ve yoğunluğu, hazırlık rejiminin tüm beden 1şınlaması (TBI) ile kombinasyonu ve allojenik HKHN (aHKHN) yapılan hastalarda uygulanan graft versus host hastalığı $(\mathrm{GVHH})$ profilaksisi OM sıklığı ve şiddetini önemli derecede arttırmaktadır $(2,9,16,19)$.

\section{Oral Mukozitin Klinik ve Ekonomik Sonuçları}

Oral mukozitte ilk klinik bulgu, oral mukozada veya dil üzerinde oluşan eritemli alanlardır (23). Oral mukozitin şiddeti ilerledikçe eritemli alanların büyüklüğünde artma, yaygın beyaz kabuklu alanlar, ağrılı ülserasyonlar ve kanama odakları gelişmektedir (24).

Oral mukozitin klinik ve ekonomik sonuçları genellikle mukozitin ileri evrelerinde görülmektedir. Ciddi mukozit, hastaların ağız boşluğunda ve/veya boğazlarında şiddetli ağrı yaşamalarına ve dolayısıyla opioid analjezik kullanımına neden olmaktadır $(3,9)$. Ağrı, hastaların çiğneme, yutma ve konuşma yeteneklerini bozarak yetersiz sıvı/besin alımına, malnütrisyona ve iletişim sorunlarına yol açmaktadır $(3,8)$. Yeterince beslenemeyen hastalarda kilo kaybı, dehidratasyon, mukozada ülserasyon, sıv1-elektrolit dengesizliği gelişebilmekte ve total parenteral beslenme (TPB) başlanabilmektedir (18, 25). Sonuçta, hastaların hastanede yatış süreleri uzamakta, tedavi maliyetleri artmakta ve yaşam kaliteleri bozulmaktadır $(9,26)$. Yapılan bir meta-analiz çalışmasında; OM'si olmayan hastaların ortalama hastanede yatış maliyeti KT siklusu başına 3893 dolar iken OM'li hastalar için ortalama hastanede yatış maliyetinin KT siklusu başına 6277 dolar olduğu belirtilmektedir (27).

Oral kanama ve enfeksiyon OM'nin diğer önemli komplikasyonlarıdır. Ülserleşmiş oral mukoza mikroorganizmalar için giriş kapısı oluşturarak bakteriyel/fungal/viral enfeksiyon gelişme riskini arttırmaktadır. Enfeksiyonlar, yalnızca oral mukozada sınırlı kalabileceği gibi, sistemik enfeksiyon ve septisemi de gelişebilmektedir (28). Kanser tedavisinin yan etkisi olan trombositopeni hastaları oral kanama ve ülserasyonlara daha duyarlı hale getirmektedir. Diş çürügüu, periodontal hastalık, uygun olmayan protezler ve buna benzer diğer problemler, kanser tedavisine başlamadan önce çözülmelidir (29).

Şiddetli OM'ye bağlı olarak gelişen semptomlar, TPB ihtiyacı, febril nötropeni, tekrarlayan enfeksiyonlar ve analjezik gereksinimi hastanede yatış süresinin uzamasına, sekonder komplikasyonların gelişmesine, ek tedavi maliyetine, günlük yaşam aktivitelerinin bozulmasına ve yaşam kalitesinde azalmaya neden olmaktadır (9, 27, 30). Ayrıca hastalar içe kapanma, uykusuzluk, huzursuzluk, anksiyete, depresyon ve sosyal izolasyon gibi psikososyal sorunlar da yaşamaktadır $(3,30,31)$.

\section{Oral Mukozitin Dĕgerlendirilmesi}

Oral mukozitin şiddetini belirlemede çok sayıda ölçek kullanılmaktadır. Bu ölçeklerden Dünya Sağlık Örgütü Oral Toksisite Skalası (WHO OTS - World Health Organization Oral Toxicity Scale) klinik uygulamada sıklıkla tercih edilen kullanımı kolay bir ölçektir. DSÖ’ye göre OM anatomik, semptomatik ve fonksiyonel yönlerden evre 0 ile 4 arasında derecelendirilmektedir. Diğer ölçeklerden bazıları; Ağız Değerlendirme Rehberi (OAG - Oral Assesment Guide), Ulusal Kanser Enstitüsü Yan Etkiler için Genel Terminoloji Kriterleri (NCI-CTC - National Cancer Institute - Common Terminology Criteria for Adverse Event), Kanser Hemşireliği Araştırma Batı Konsorsiyumu (WCCNR - Western Consortium for Cancer Nursing Research) Stomatit Evreleme Sistemi, Radyasyon Tedavisi Onkoloji Grubu (RTOG - Radiation Therapy Oncology Group) Evreleme Sistemi ve Oral Mukozit Değerlendirme Skalasıdır (OMAS - Oral Mucositis Assessment Scale) (Tablo 1). (2, 32-35) 
Tablo 1. Oral Mukozit Puanlama Ölçekleri

\begin{tabular}{|c|c|c|c|c|c|c|}
\hline & 0 & 1 & 2 & 3 & 4 & 5 \\
\hline $\begin{array}{l}\text { Dünya Sağllk Örgütü Oral } \\
\text { Toksisite Skalası (World } \\
\text { Health Organization Oral } \\
\text { Toxicity Scale) }\end{array}$ & Normal & $\begin{array}{l}\text { Hassasiyet } \\
\quad \pm \\
\text { eritem }\end{array}$ & $\begin{array}{l}\text { Eritem, ülserler } \\
\text { Hasta katı gıdalar alabilir }\end{array}$ & $\begin{array}{l}\text { Ülserler, yaygın eritem } \\
\text { Hasta katı gıdaları alamaz }\end{array}$ & $\begin{array}{c}\text { Mukozit çok } \\
\text { yaygın } \\
\text { Şiddetli ağrı ve } \\
\text { kanama var } \\
\text { Oral beslenme } \\
\text { mümkün değildir }\end{array}$ & - \\
\hline \multicolumn{7}{|c|}{$\begin{array}{l}\text { Ağız Değerlendirme Rehberi (Oral } \\
\text { Assesment Guide-OAG) }\end{array}$} \\
\hline Ses & - & Normal & Normalden daha boğuk veya çatlak & Konuşma sırasında zorlanıyor & - & - \\
\hline Yutkunma & - & Normal & Yutkunma sırasında hafif ağr1 & Yutkunamiyor & - & - \\
\hline Dudaklar & - & Pürüzsüz, pembe ve nemli & Kuru veya çatlamış & Dudaklarda yara veya kanama var & - & - \\
\hline Dil & - & $\begin{array}{l}\text { Pembe ve nemli, papilla } \\
\text { mevcut }\end{array}$ & $\begin{array}{l}\text { Kızarık veya kızarıklık olmadan dilin } \\
\text { üstü kirli sarı bir tabakayla kaplanmış }\end{array}$ & Çatlamış & - & \\
\hline Tükürük & - & Sulu & Koyu veya yapışkan & Yok & - & - \\
\hline Oral mukoza & - & Pembe ve nemli & $\begin{array}{l}\text { Kırmızı veya beyaz bir tabaka ile } \\
\text { kaplanmış, ağız yarası yok }\end{array}$ & Ağı yarası var \pm kanama & - & - \\
\hline Diş etleri & - & Pembe ve normal & Ödemli \pm kızarıklık & $\begin{array}{c}\text { Kanama var (spontan ya da basınç } \\
\text { uygulaması ile) }\end{array}$ & - & - \\
\hline Dişler/protez & - & Temiz, ölü doku yok & - & $\begin{array}{c}\text { Diş ve dişeti arasındaki sınırda veya } \\
\text { protezin yerleştiği alanda plak ya da ölü } \\
\text { doku mevcut }\end{array}$ & ü & - \\
\hline $\begin{array}{l}\text { Total Oral Mukoza Puanı } \\
\text { (OMP) }\end{array}$ & $\begin{array}{l}8-14 \\
14-2 \\
\end{array}$ & $\begin{array}{l}\text { 219 Oral müköz membrand } \\
\text { T045 Oral müköz membranc }\end{array}$ & $\begin{array}{l}\text { zulma riski } \\
\text { ozulma }\end{array}$ & & & \\
\hline \multicolumn{7}{|c|}{$\begin{array}{l}\text { Kanser Hemşireliği Araştırma Batı Konsorsiyumu (WCCNR-Western Consortium for Cancer Nursing } \\
\text { Research) Stomatit Evreleme Sistemi }\end{array}$} \\
\hline Lezyon & Yok & $1-4$ & $>4$ & $\begin{array}{l}\text { Ağız yüzeyinin }>\% 50 \\
\text { lezyonlarda birleşme }\end{array}$ & - & - \\
\hline Renk & Pembe & Hafif kirmızı & Orta derecede kırmızı & Çok kırmızı & - & - \\
\hline Kanama & Yok & - & Yemek veya ağız bakımı esnasında & Kendiliğinden & - & - \\
\hline $\begin{array}{l}\text { Radyasyon Tedavisi Onkoloji } \\
\text { Grubu (RTOG - Radiation } \\
\text { Therapy Oncology Group) }\end{array}$ & Normal & Eritem & $\begin{array}{l}<1.5 \mathrm{~cm} \text { yamalı lezyon, birbiri ile } \\
\text { birleşik değil }\end{array}$ & $\begin{array}{l}<1.5 \mathrm{~cm} \text { küçük yamalı lezyon, } \\
\text { birbiri ile birleşik }\end{array}$ & $\begin{array}{l}\text { Derin ülserler } \pm \\
\text { kanama }\end{array}$ & - \\
\hline
\end{tabular}


Tablo 1 Devamı. Oral Mukozit Puanlama Ölçekleri

1 2

3

Ulusal Kanser Enstitüsü Yan Etkiler için Genel Terminoloji Kriterleri (NCI-CTC-

National Cancer Institute Common Terminology Criteria for Adverse Event)

Kemoterapiye bağlı stomatit / farenjit (oral Yok Ağrısız ülserler, eritem ya da

/ farengeal mukozit) lezyon olmaksızın hafif ağrı
Ağrısız ülserler, eritem ya da lezyon olmaksızın hafif ağrı
HKHN (stomatit / farenjit, oral / farengeal Yok mukozit)
Ağrılı eritem, ödem ya da ülserler, fakat oral beslenme mümkündür

Ağrılı eritem, ödem ya da ülserler, fakat oral beslenme mümkündür
A ğrılı eritem, ödem

ya da ülserler

intravenöz hidrasyon gereklidir veya yutmay 1 önleyen veya hidrasyon veya parenteral (veya enteral) beslenme desteği gerektiren ülserler

Yamal1, psödomembranöz reaksiyon (en büyük boyutta ve bitişik olmayan genellikle $<1.5 \mathrm{~cm}$ yamalar)

Psödomembranöz reaksiyon (en büyük boyutta genellikle $>1.5 \mathrm{~cm}$ bitişik
Şiddetli ülserasyon,

beslenme desteği ya da

Profilaktik entübasyon

belgelenmis aspirasyon Toksisite yamalar) parenteral ya da enteral

profilaktik entübasyon gereklidir gerektiren veya pnömonisi ile ile ilgili sonuçlanan cidd ölüm

Toksisite ile ilgili ölüm

$$
\text { ülserasyon }
$$

Ülserasyon ve ara sira kanama ufak travma

veya aşınma ile uyarılmaz

Oral Mukozit Değerlendirme Skalası

(OMAS - Oral Mucositis Assessment Scale)

Üst dudak

Alt dudak

Sağ yanak

Sol yanak

Sağ ventral ve lateral dil

Ağız tabanı

Yumuşak damak

Sert damak 


\section{Oral Mukozitin Önlenmesi ve Tedavisi}

Kanser tedavisine başlamadan önce ağız boşluğu muayenesinin yapılarak normal ve anormal durumların belirlenmesi önemlidir (28).

Oral mukozitin önlenmesi ve tedavisinde kanıta dayalı klinik uygulama rehberleri bulunmaktadır. Bunlardan biri, Çok Uluslu Kanser Destek Bakım Birliği/Uluslararası Oral Onkoloji Birliği [MASCC/ISOO (The Mucositis Study Group of the Multinational Association of Supportive Care in Cancer/International Society of Oral Oncology)] tarafindan geliştirilmiştir (36). Kanser tedavisi alan hastalarda OM'yi önlemede temel ağız bakımının önemini vurgulayan MASCC/ISOO, OM için temel ağız bakımı stratejileri hakkında üç set klinik uygulama rehberi yayınlamıştır. 2004 ve 2007'de yayınlanan ilk iki rehberde, kanser tedavisinin neden olduğu OM'yi azaltmak için ağız bakımı protokollerinin kullanılması önerilmiştir. 2007 MASCC/ISOO kılavuzunda, mevcut kanıtlara dayanarak kanser tedavisinden önce diş hekimi değerlendirmesi, klinik muayene için onaylanmış araçların kullanımı, hastanın kendi kendine raporu, ağız bakımına disiplinlerarası bir yaklaşım, düzenli ve sistematik ağız bakım rejiminin uygulanması onaylanmıştır. Ağız bakım rejimi, yumuşak bir diş firçası ile diş fırçalamayı, düzenli diş fırçasını değiştirmeyi, diş ipi kullanımını, yumuşak çözeltiler ile gargarayı ve nemlendiricilerin kullanımını içermektedir. (36). Son olarak 2019 yılında MASCC / ISOO kılavuzu güncellenmiştir. Son güncelleme ile kılavuza OM'nin önlenmesine katkıda bulunabilecek hasta eğitimi eklenmiştir (37). Diğer rehber ise, Amerikan Onkoloji Hemşireliği Derneği [ONS (Oncology Nursing Society)] tarafından geliştirilmiştir. Bu rehber de, MASCC/ISOO’ya benzer şekilde 2019 yılında güncellenmiştir. Rehberde, uygulama için önerilen ve etkili olması muhtemel tedaviler yer almaktadır (38).

Oral mukozitin önlenmesi/tedavisinde kullanılan farmakolojik ve farmakolojik olmayan ürünler şunlardır:

\section{Farmakolojik Ürünler}

Benzidamin hidroklorid: Lokal analjezik, anestetik, antioksidan ve antienflamatuvar etkileri bulunan steroid olmayan bir ilaçtır (39). Yapılan çalışmalarda, baş-boyun bölgesinden RT alan hastalara uygulanan benzidamin hidrokloridinin OM'nin başlama zamanı, sıklığı, şiddeti ya da süresinde azalma sağladığı saptanmıştır (40-42). MASSC/ISOO kanıta dayalı klinik uygulama rehberinde de, KT olmadan orta doz RT alan (50 Gy'ye kadar) baş ve boyun kanserli hastalarda OM'yi önlemek için benzidamin gargara kullanımı önerilmektedir (kanıt düzeyi I) (43).

Klorheksidin: Antimikrobiyal özelliği bulunmaktadır (44). Yapılan çalışmalarda, OM'nin şiddetini önlemede ya da azaltmada önemli bir etkisinin olmadığ belirtilmektedir $(45,46)$. Tat algısında değişme, dil ve dişlerde lekelenme gibi yan etkileri bulunmaktadır (46). MASSC/ISOO kanıta dayalı klinik uygulama rehberinde, baş-boyun RT'si (kanıt düzeyi III) uygulanan hastalarda OM'yi önlemek için klorheksidin kullanımı önerilmemektedir (37).

Sukralfat: Oral ve gastrointestinal sistem ülserlerinin tedavisinde kullanılmaktadır (45). Ala ve arkadaşlarının (2016) yaptığı çalışmada, sukralfatın 5-Fu kaynaklı OM'nin sıklığı ve şiddetinde azalma sağladığı saptanmıştır (47). MASSC/ISOO kanıta dayalı klinik uygulama rehberinde de, RT ile tedavi edilen baş-boyun kanseri hastalarında OM ile ilişkili ağrının önlenmesi için kombine topikal ve sistemik sukralfat kullanımı (kanıt düzeyi II), RT ile tedavi edilen baş-boyun kanseri hastalarında OM ile ilişkili ağrının tedavisi için topikal sukralfat kullanımı (kanıt düzeyi III) ve KT ile tedavi edilen solid kanseri olan hastalarda OM ile ilişkili ağrının tedavisi için kombine topikal ve sistemik sukralfat kullanımı önerilmemektedir (kanıt düzeyi II) (48).

Palifermin (Rekombinant İnsan Keratinosit Büyüme Faktörü): Çeşitli dokularda epitel hücrelerinin büyümesini uyarmaktadır (49). Adil ve arkadaşlarının (2019) HKHN sonrası paliferminin OM ve aGvHH üzerindeki etkinliğini değerlendirmek için yaptıkları metaanaliz çalışmada, güncel vaka kontrol çalışmalarının metaanalizinde palifermin tedavisinin OM'nin insidansını ve ciddiyetini önemli ölçüde azalttı̆̆ı, ancak randomize kontrollü çalışmalarda OM derecelerinde anlamlı bir fark bulunmadığı saptanmıştır (50).

Kalsiyum fosfat elektrolit çözeltisi: FDA tarafından onaylanmış bir ilaçtır (51). Farklı kanser tedavileri alan hastalar ile yapılan çalışmalarda kalsiyum fosfat elektrolit çözeltisinin OM'nin insidansını, şiddetini ve süresini azaltmada etkili olmadığ 1 gösterilmiştir (52-54).

Çinko sülfat: Homeostazın sürdürülmesinde, yara iyileşmesinde ve bağışıklık sistemini güçlendirmede etkilidir (55). Rambod ve arkadaşlarının yaptığı çalışmada (2018), çinko sülfatın KT alan lösemi hastalarında OM'nin insidansını ve şiddetini azalttığı saptanmıştır (56). Metaanaliz çalışmada ise, oral çinko sülfatın kanser hastalarında KT'nin indüklediği OM'nin insidansını ve şiddetini önleme veya azaltmada herhangi bir klinik faydası olamayacağı sonucuna varılmıştır (57).

Glutamin: Glutamin vücutta bol miktarda bulunan çok yönlü bir aminoasittir (58). On beş çalışmanın dahil edildiği sistematik derlemede, KT ve/veya RT alan hastalarda oral glutaminin mukozit süresini, şiddetini ve başlangıç zamanını azaltmada etkili olduğu bulunmuştur (59). Pathak ve arkadaşlarının (2019) orofarenks ve larenks karsinomalı hastalarda kemoradyoterapiye (KRT) bağlı OM ve disfajinin tedavisinde oral glutaminin rolünü ve etkinliğini belirlemek amacıyla yaptıkları randomize kontrollü çalışmada, glutaminin OM ve disfajinin insidansını ve ciddiyetini önemli ölçüde azalttığı ve başlamasını geciktirdiği bildirilmektedir (60). Diğer çalışmada ise, glutaminin şiddetli mukozitin önlenmesinde yararlı olabileceği fakat kanıtların zayıf olduğu belirtilmektedir (61). MASSC/ISOO kanıta dayalı klinik uygulama rehberinde de, KT ile birlikte RT alan baş ve boyun kanseri hastalarında OM'nin önlenmesi için oral glutamin kullanımı önerilmektedir (kanıt düzeyi II) (55).

Düşük doz lazer tedavisi: Profilaktik düşük doz lazer tedavisi, şiddetli mukoziti ve ağrıyı azaltmaktadır (62, 63). Silva ve arkadaşlarının (2015) YDKT alan ve HKHN uygulanan hastalar ile yaptığı çalışmada, düşük doz lazer tedavisi uygulanan hastaların \%72.8'inde derece 0-1, \%27.2'sinde derece 2 OM geliştiği ve hastaların hiçbirinde derece 3 veya 4 OM gelişmediği saptanmıştır (64). MASCC / ISOO kanıta dayalı klinik uygulama rehberinde de, TBI olan veya olmayan, YDKT ile şartlandırılmış HKHN yapılan yetişkin hastalarda (kanıt düzeyi I), KT almaksızın baş-boyun bölgesine RT uygulanan yetişkin 
hastalarda (kanıt düzeyi II) ve baş-boyun kanseri için RT ve KT alan yetişkin hastalarda (kanıt düzeyi I) OM'nin önlenmesi için düşük seviyeli lazer tedavisi kullanılarak ağız içi fotobiyomodülasyon tedavisinin kullanımı önerilmektedir (65).

Farmakolojik Olmayan Ürünler

Kriyoterapi (Oral soğutma): Özellikle bolus KT uygulaması sırasında ağız içerisine buz parçacıklarının yerleştirilmesi ile uygulanan ucuz ve kolay bir profilaktik tedavi yöntemidir. Kriyoterapi lokal vazokonstrüksiyon ile oral mukozaya olan kan akımını azaltmaktadır. Böylece mukozadaki epitelyal ve bazal hücrelerin metabolik fonksiyonları en aza inerek OM gelişimi önlenmektedir (66). Yapılan sistematik inceleme ve metaanaliz çalışmada, oral kriyoterapinin YDKT alan hastalarda OM insidansını ve şiddetini anlamlı derecede azalttığı belirlenmiştir (67). MASCC / ISOO kanıta dayalı klinik uygulama rehberinde de, yüksek doz melfalan hazırlama rejimleri ile otolog HKHN yapılan hastalar (kanıt düzeyi II) ve bolus 5-Fu KT alan hastalar için OM'nin önlenmesinde oral kriyoterapi kullanımı önerilmektedir (kanıt düzeyi II) (68).

Bal: Antibakteriyel, antimikrobiyal ve analjezik özellikleri bulunmaktadır (69). Dokuz çalışmanın dahil edildiği baş boyun kanserli hastalarda RT sırasında OM tedavisinde kullanılan balın etkinliğinin incelendiği bir metaanaliz çalışmasında, tedavinin ilk 3 haftasında orta ila şiddetli mukozit görülme sıklığı ve ortalama mukozit derecesi bal grubunda kontrol grubuna göre anlamlı derecede düşük bulunmuştur. Aynı çalışmada, mukozit başlangıcı bal grubunda kontrol grubuna göre anlamlı olarak daha geç olmuştur (70). Yedi randomize kontrollü çalışmanın dahil edildiği bir metaanaliz çalışmasında, beş çalışmada balın RT/KT kaynaklı mukozit tedavisi üzerindeki profilaktik etkisinin olduğu gösterilmiştir (71). Yapılan bir sistematik analizde; balın RT ve KT ile ilişkili OM'nin şiddetinde azalma sağladığı saptanmıştır (72). Kemoterapi ile ilişkili OM'si olan hastalarda topikal steroid, bal ve bal ile birlikte kahvenin tedavi edici etkilerini karşılaştırmak amacıyla yapılan bir çalışmada; bal ve kahve karışımının lezyonların şiddetini azaltmada daha etkili olduğu gösterilmiştir (73). Khanjani ve arkadaşlarının (2019), KT alan 53 akut miyeloid lösemi (AML) hastası ile yaptıkları çalışmada ise, ballı gargaranın mukozit ve kilo kaybının şiddetini önlemede ve azaltmada etkili olduğu belirtilmektedir (74).

Propolis: Antienflamatuvar, antibakteriyel, antifungal, antioksidan, antiviral ve antikanserojenik etkiler göstermektedir (75-78). Baş ve boyun kanseri olan hastalar ile yapılan bir pilot çalışmada, propolisin su bazlı ekstraktının, RT kaynaklı mukoziti etkili bir şekilde önlediği ve iyileştirdiği saptanmıştır (79). Piredda ve arkadaşlarının (2017) yaptıkları çalışmada da, propolisin adjuvan KT alan meme kanserli hastalarda OM'yi önlemede güvenli, iyi tolere edilebilir ve etkili bir ürün olduğu bulunmuştur (80).

E vitamini: Antioksidan özelliği bulunmaktadır. Chaitanya ve arkadaşlarının (2017) metaanaliz çalışmasında, E vitamininin topikal uygulamasının sistemik uygulamaya göre OM üzerine daha iyi sonuç verdiği bildirilmektedir (81).

Selenyum: Antioksidan ve antienflamatuvar özellikleri olan temel bir eser elementtir (82). Ameri ve arkadaşlarının (2016) baş boyun kanserli hastalarda RT'ye bağlı OM'nin hafifletilmesinde oral selenyumun etkinliğini değerlendirdikleri plasebo kontrollü bir pilot çalışmada, oral selenyumun RT'ye bağlı OM'nin önlenmesinde etkili olduğu ve iyi tolere edildiği saptanmıştır (83).

Aloe Vera: Antioksidan, antienflamatuvar, antiartritik, antikanser ve antidiyabetik özellikleri bulunmaktadır (84). Bazı çalışmalarda, Aloe veranın radyasyona bağlı ülserlerin ve mukozitin önlenmesi ve tedavisi üzerindeki olumlu etkileri gösterilmiştir (85).

Karadut: Antienflamatuvar, antioksidatif ve analjezik etkileri bulunmaktadır (86, 87). Demir Doğan ve arkadaşlarının (2017), RT alan baş ve boyun kanserli hastalarda karadut pekmezinin OM'nin önlenmesindeki etkinliğini değerlendirmek amacıyla yaptıkları randomize kontrollü çalışmada, karadut pekmezi grubunda OM insidansı ve şiddetinin daha düşük olduğu saptanmıştır (88). Harman ve arkadaşlarının (2019) HKHN yapılan hastalarda klorheksidin glukonat ve benzidamin hidroklorür, kalsiyum-fosfat çözeltisi ve karadut şurubunun OM üzerine etkisini belirlemek amacıyla yaptıkları çalışmada, karadut şurubunun OM'nin önlenmesinde ve tedavisinde faydalı olduğu gösterilmiştir (89).

\section{Oral Mukozitin Önlenmesi ve Tedavisinde Hemşirenin Rolii}

Kanser hastalarının normal yaşam süreçleri ve öncelikleri değişmektedir. Hastalık ve tedavinin getirdiği zorluklar, hastaların önleyici ağı bakımına verdikleri önem ve ilginin azalmasına ve temel ağız bakımlarını ertelemeye neden olmaktadır. Bu ihmal, kanser tedavisi sırasında ve daha sonraki yaşamlarında ağız boşluğu problemleri potansiyeline katkıda bulunmaktadır (90).

Ağız mukozasının değerlendirilmesi ve bakımı, KT/RT alan hastalara bakım veren hemşirelerin önemli klinik müdahaleleri arasında yer almaktadır. Ağı boşluğunun geçerli ve güvenilir bir ölçüm aracı ile sistematik olarak incelenmesi, hemşirelik müdahalelerine rehberlik etmede önemli bilgiler sağlamaktadır (91). Yaygın olarak kullanılan OM değerlendirme ölçeği Dünya Sağlık Örgütü Oral Toksisite Skalası (DSÖOTS) ağız içindeki tüm yapıları anatomik, semptomatik ve fonksiyonel olarak değerlendirmektedir (7). Ağı içi muayenesi ve bakımı, tanıdan itibaren başlayan, tedavi süreci ve yaşamın sonuna kadar devam eden kanser bakımına entegre bir yaklaşımdır. Hastanın tedavi öncesi, tedavi süreci ve taburculuktan sonra tüm yaşamı süresince ağı içindeki tüm değişiklikler (enflamasyon, renk değişikliği, ülser, kanama vb.) izlenmeli, değerlendirilmeli ve bakımı sürdürülmelidir. Özellikle tedavi öncesi, hasta ve tedaviyle ilişkili risk faktörleri dikkate alınarak hemşirelik değerlendirmesinin yapılması, hastanın olağan ağız bakımı uygulamaları ve ağız bakımı yapabilme yeteneğinin belirlenmesi ilk müdahaleyi oluşturmaktadır. Oral değerlendirme, rutin devam eden bir süreçtir ve elde edilen veriler, oral mukozadaki değişiklikleri analiz etme, tedaviyi değerlendirme ve kanıta dayalı müdahalelerin uygulanması ile birlikte kişiselleştirilmiş bir bakım planı geliştirmeye olanak tanımaktadır $(92,93)$. Oral mukozit gelişen hastalarda değerlendirme sıklığı arttırılmalı, her şiftteki hemşire en az bir kez hastanın ağız içi değerlendirmesini yapmalı, OM'ye bağlı gelişen yüksek ateş, iştahsızlık, bulantı, kilo kaybı vb. gibi diğer semptomları da izlemeli, doktor istemine göre yara kültürü almalı ve kanıta dayalı bakım sunmalıdır. Bununla birlikte, hastalara belirli aralıklarla "ağzınızla ilgili herhangi bir sorununuz var mı?" veya "ağzınızda herhangi bir değişiklik fark ettiniz mi?” gibi sorular sorulması, oral mukozalarını muayene etme ve günlük izleme 
tekniklerinin öğretilmesi, OM belirtileri ve komplikasyonlarının izlenmesi, ağız hijyenini sürdürme, uygun solüsyonlar ile gargara yapma, dudakları nemlendirme, uygun beslenme, kserostomi kontrolü ve mukozayı tahriş edici maddelerin ve yiyeceklerin alınmaması konularında desteklenmesi ve eğitim verilmesi hastada farkındalık oluşturarak kendi bakımına katılımını arttıracaktır (37). Ağız boşluğundaki değişiklikleri tespit etmek için yapılan değerlendirmeler ve hasta bildirimleri erken bireysel müdahale olanağı sağlamakla birlikte özellikle septisemi, ağrı, kanama, malnütrisyon gibi ikincil sorunların gelişmesini önleyecektir (94).

\section{Sonuç}

Sonuç olarak; OM, KT veya RT alan hastalarda gelişen önemli bir komplikasyonudur. Özellikle baş-boyun RT'si veya YDKT alan hastalarda OM sıklığı ve şiddeti artmaktadır. OM'nin klinik sonuçları, yaşam kalitesinin azalmasına ve tedavi maliyetlerinin artmasına neden olmaktadır. Kanıta dayalı klinik uygulama rehberlerinde OM'nin önlenmesinde benzidamin gargara, düşük seviyeli lazer tedavisi, oral kriyoterapi ve oral glutaminin kullanımı önerilmektedir. Bu tedavilerin kullanımı ile OM'nin insidansı veya şiddeti anlamlı derecede azalmasına rağmen yeni çalışmalar ile desteklenmelidir.

Oral mukozitin önlenmesi veya tedavisinde, onkoloji hemşiresinin ağız boşluğunu değerlendirebilme, toksisite süreci, mukozit evreleri ve beklenen değişiklikleri bilme ve anlama becerisi ve kanıta dayalı uygulama bilgisi, önerilen standart bakımın temelini oluşturmaktadır. Hemşireler, OM'yi geçerliliği kanıtlanmış ölçeklerle değerlendirmeli, OM'nin önlenmesine yönelik geliştirilen kanıta dayalı rehberleri takip ederek uygulamalarını güncellemelidir.

\section{Bilgilendirme}

Yazarların katkı oranı eşittir. Yazarlar arasında çıkar çatışması bulunmamaktadır.

\section{Kaynaklar}

1. Maria OM, Eliopoulos N, Muanza T. Radiation-induced oral mucositis. Front Oncol 2017;7:89.

2. Chaudhry HM, Bruce AJ, Wolf RC, Litzow MR, Hogan WJ, Patnaik MS, et al. The incidence and severity of oral mucositis among allogeneic hematopoietic stem cell transplantation patients: a systematic review. Biol Blood Marrow Transplant 2016;22(4):605-616.

3. Kamińska M, Juszkiewicz M, Tymicka R, Bronikowska A, Kolak A. Procedure in the prevention and nurturing of inflammatory changes of oral mucositis among patients treated for oncological conditions. Medical Studies/Studia Medyczne. 2016;32(2):145-149.

4. Barkokebas A, Silva IHM, De Andrade SC, Carvalho AAT, Gueiros LAM, Paiva SM, et al. Impact of oral mucositis on oral-health-related quality of life of patients diagnosed with cancer. Journal of Oral Pathology \& Medicine. 2015;44(9):746-751.

5. Schub E, Gilberto C. Stomatitis (Oral mucositis), Cancer treatment-induced. Cinahl Information Systems 2017.

6. Wilberg P, Hjermstad MJ, Ottesen S, Herlofson BB. Chemotherapy-associated oral sequelae in patients with cancers outside the head and neck region. J Pain Symptom Manage 2014;48(6):1060-1069.

7. Çakmak S, Nural N. Incidence of and risk factors for development of oral mucositis in outpatients undergoing cancer chemotherapy. Int J Nurs Pract 2019;25(1):e12710.

8. Mercadante S, Aielli F, Adile C, Ferrera P, Valle A, Fusco F, et al. Prevalence of oral mucositis, dry mouth, and dysphagia in advanced cancer patients. Support Care Cancer 2015;23(11):3249-3255.

9. Staudenmaier T, Cenzer I, Crispin A, Ostermann H, Berger K. Burden of oral mucositis in stem cell transplant patientsthe patients' perspective. Support Care Cancer 2018;26(5):1577-1584.

10. Jo KS, Kim NC. Incidence and factors influencing oral mucositis in patients with hematopoietic stem cell transplantation. J Korean Acad Nurs 2014;44(5):542-551.

11. Luitel A, Rimal J, Maharjan IK, Regmee P. Assessment of oral mucositis among patients undergoing radiotherapy for head and neck cancer. Kathmandu Univ Med J 2019;65(1):63-67.

12. Bilodeau EA, Lalla RV. Recurrent oral ulceration: Etiology, classification, management, and diagnostic algorithm. Periodontology 2019;80(1):49-60.

13. Leite Cavalcanti A, José de Macêdo D, Suely Barros Dantas F, dos Santos Menezes K, Filipe Bezerra Silva D, Alves de Melo Junior W, et al. Evaluation of oral mucositis occurrence in oncologic patients under antineoplastic therapy submitted to the low-level laser coadjuvant therapy. J. Clin. Med 2018;7(5):90.

14. Al-Ansari S, Zecha JAEM, Barasch A, de Lange J, Rozema FR, Raber-Durlacher JE. Oral mucositis induced by anticancer therapies. Curr Oral Health Rep 2015;2(4):202-211.

15. Moslemi D, Nokhandani AM, Otaghsaraei MT, Moghadamnia Y, Kazemi S, Moghadamnia AA. Management of chemo/radiation-induced oral mucositis in patients with head and neck cancer: A review of the current literature. Radiother Oncol. 2016;120(1):13-20.

16. Shouval R, Kouniavsky L, Fein J, Danylesko I, Apel A, Shem-Tov N, et al. Determinants for oral mucositis in allogeneic hematopoietic stem cell transplantation: prospective evaluation and risk analysis. Blood. 2017;130(Supplement 1):3239.

17. Sonis ST. Pathobiology of oral mucositis: Novel insights and opportunities. J. Support. Oncol. 2007;5(9 Suppl 4), 3-11.

18. Sakellari I, Angelopoulou M, Tsopra O, Dervenoulas I, Tsirigotis P, Spyridonidis A, et al. A prospective study of incidence, clinical and quality of life consequences of oral mucositis post palifermin prophylaxis in patients undergoing high-dose chemotherapy and autologous hematopoietic cell transplantation. Ann Hematol 2015;94(10):1733-1740. 
19. Valeh M, Kargar M, Mansouri A, Kamranzadeh H, Gholami K, Heidari K, et al. Factors affecting the incidence and severity of oral mucositis following hematopoietic stem cell transplantation. Int J Hematol Oncol Stem Cell Res. 2018;12(2):142-152.

20. Saedi HS, Gerami H, Soltanipour S, Habibi AF, Mirhosseyni M, Montazeri S, et al. Frequency of chemoradiotherapyinduced mucositis and related risk factors in patients with the head-and-neck cancers: A survey in the North of Iran. J. Dent. Res 2019;16(5):354-359.

21. Gussgard AM, Jokstad A, Wood R, Hope AJ, Tenenbaum H. Symptoms reported by head and neck cancer patients during radiotherapy and association with mucosal ulceration site and size: an observational study. Plos One. 2015;10(6):e0129001.

22. Curra M, Soares Junior LAV, Martins MD, Santos PSDS. Chemotherapy protocols and incidence of oral mucositis. An integrative review. Einstein (São Paulo). 2018;16(1):1-9.

23. Shumsky A, Bilan E, Sanz E, Petrovskiy F. Oncoxin nutritional supplement in the management of chemotherapy- and/or radiotherapy-associated oral mucositis. Mol Clin Oncol. 2019;10(4):463-468.

24. Epstein JB, Saunders DP. Managing oral mucositis in cancer therapy. [online]. 1 Temmuz 2015. http://www.oralhealthgroup.com/features/managing-oral-mucositis-cancer-therapy. 17 Eylül 2019.

25. Eduardo FdP, Bezinelli LM, Gobbi MF, Pereira AZ, Vogel C, Hamerschlak N, et al. Impact of oral and gastrointestinal mucositis on body weight alterations during hematopoietic stem cell transplantation. Nutr Cancer 2018;70(2):241-248.

26. Pereira NF, Silva PVRD, Fukuoka CY, Michel-Crosato E, Gonçalves AS, Alves FA, et al. Measurement of oral health quality of life among patients who underwent haematopoietic stem-cell transplantation. Braz. Oral Res. 2018;32:e78.

27. Kuo CC, Wang RH, Wang HH, Li CH. Meta-analysis of randomized controlled trials of the efficacy of propolis mouthwash in cancer therapy-induced oral mucositis. Support Care Cancer 2018; 26(12):4001-4009.

28. Elad S, Raber-Durlacher JE, Brennan MT, Saunders DP, Mank AP, Zadik Y, et al. Basic oral care for hematologyoncology patients and hematopoietic stem cell transplantation recipients: a position paper from the joint task force of the Multinational Association of Supportive Care in Cancer/International Society of Oral Oncology (MASCC/ISOO) and the European Society for Blood and Marrow Transplantation (EBMT). Support Care Cancer 2015;23(1):223-236.

29. Gomes AOF, Silva Junior A, Noce CW, Ferreira M, Maiolino A, Torres SR. The frequency of oral conditions detected in hematology inpatients. Hematol Transfus Cell Ther 2018;40(3):240-244.

30. Franco P, Martini S, Di Muzio J, Cavallin C, Arcadipane F, Rampino M, et al. Prospective assessment of oral mucositis and its impact on quality of life and patient-reported outcomes during radiotherapy for head and neck cancer. Medical Oncology. 2017;34(5):81.

31. Jehn P, Stier R, Tavassol F, Dittmann J, Zimmerer R, Gellrich NC, et al. Physical and psychological impairments associated with mucositis after oral cancer treatment and their impact on quality of life. Oncol Res Treat 2019;42(6):342348 .

32. Olson K, Davies B, Degner L, Neufeld K, Plummer H, Thurston N, et al. Assessing stomatitis: refinement of the Western Consortium for Cancer Nursing Research (WCCNR) stomatitis staging system. Can Oncol Nurs J. 1998;8(3):160-165.

33. Baysal E, Sarı D. Hematopoetik kök hücre naklinde oral mukozitin önlemesi, bakımı ve tedavisinde güncel yaklaşımlar: Literatür incelemesi. J. Hum. Sci. 2016;13(3), 5721-5739.

34. Tavakoli Ardakani M, Ghassemi S, Mehdizadeh M, Mojab F, Salamzadeh J, Ghassemi S, et al. Evaluating the effect of Matricaria recutita and Mentha piperita herbal mouthwash on management of oral mucositis in patients undergoing hematopoietic stem cell transplantation: A randomized, double blind, placebo controlled clinical trial. Complement Ther Med 2016;29:29-34.

35. Sonis ST, Eilers JP, Epstein JB, LeVeque FG, Liggett Jr WH, Mulagha MT, et al. Validation of a new scoring system for the assessment of clinical trial research of oral mucositis induced by radiation or chemotherapy. Cancer 1999;85(10):2103-2113.

36. MASCC/ISOO Mucositis Clinical Practice Guidelines [online]. https://www.mascc.org/mucositis-guidelines. 22.10.2019.

37. Hong CHL, Gueiros LA, Fulton JS, Cheng KKF, Kandwal A, Galiti D, et al. Systematic review of basic oral care for the management of oral mucositis in cancer patients and clinical practice guidelines. Support Care Cancer 2019;27(10):39493967.

38. Mucositis [online]. https://www.ons.org/pep/mucositis. 27.02.2020.

39. Çıtlak K, Kapucu S. Kemoterapi alan hastalarda görülen oral mukozitin önlemesi ve tedavisinde güncel yaklaşımlar: Kanita dayalı uygulamalar. HUHEMFAD-JOHUFON 2015;2(1):70-77.

40. Chitapanarux I, Tungkasamit T, Petsuksiri J, Kannarunimit D, Katanyoo K, Chakkabat C, et al. Randomized control trial of benzydamine $\mathrm{HCl}$ versus sodium bicarbonate for prophylaxis of concurrent chemoradiation-induced oral mucositis. Support Care Cancer 2018;26(3):879-886.

41. Rastogi M, Khurana R, Revannasiddaiah S, Jaiswal I, Nanda SS, Gupta P, et al. Role of benzydamine hydrochloride in the prevention of oral mucositis in head and neck cancer patients treated with radiotherapy (>50 Gy) with or without chemotherapy. Support Care Cancer. 2017;25(5):1439-1443.

42. Sheibani KM, Mafi AR, Moghaddam S, Taslimi F, Amiran A, Ameri A. Efficacy of benzydamine oral rinse in prevention and management of radiation-induced oral mucositis: A double-blind placebo-controlled randomized clinical trial. AsiaPac J Clin Onco. 2015;11(1):22-27. 
43. Ariyawardana A, Cheng KKF, Kandwal A, Tilly V, Al-Azri AR, Galiti D, et al. Systematic review of anti-inflammatory agents for the management of oral mucositis in cancer patients and clinical practice guidelines. Support Care Cancer 2019;27(10):3985-3995.

44. Chaveli-López B, Bagán-Sebastián JV. Treatment of oral mucositis due to chemotherapy. J Clin Exp Dent 2016;8(2):e201-e209.

45. Soylu Özler G, Okuyucu Ş, Akoğlu E. The efficacy of sucralfate and chlorhexidine as an oral rinse in patients with recurrent aphthous stomatitis. Adv Med 2014; doi:10.1155/2014/986203.

46. Cardona A, Balouch A, Abdul MM, Sedghizadeh PP, Enciso R. Efficacy of chlorhexidine for the prevention and treatment of oral mucositis in cancer patients: a systematic review with meta-analyses. J Oral Pathol Med 2017;46(9):680-688.

47. Ala S, Saeedi M, Janbabai G, Ganji R, Azhdari E, Shiva A. Efficacy of sucralfate mouth wash in prevention of 5fluorouracil induced oral mucositis: a prospective, randomized, double-blind, controlled trial. Nutr Cancer 2016;68(3):456-463.

48. Saunders DP, Rouleau T, Cheng K, Yarom N, Kandwal A, Joy J, et al. Systematic review of antimicrobials, mucosal coating agents, anesthetics, and analgesics for the management of oral mucositis in cancer patients and clinical practice guidelines. Support Care Cancer 2020; 21 (11): 3191-3207.

49. Mozaffari HR, Payandeh M, Ramezani M, Sadeghi M, Mahmoudiahmadabadi M, Sharifi R. Efficacy of palifermin on oral mucositis and acute GVHD after hematopoietic stem cell transplantation (HSCT) in hematology malignancy patients: a meta-analysis of trials. Wspolczesna Onkol 2017;21(4):299-305.

50. Adil M, Sriram S, Azharuddin M, Ghosh P, Sharma M. PCN4 Effect of palifermin on oral mucositis and acute GVHD after allogeneic hematopoietic stem cell transplantation in patients with hematologic malignancy: a meta-analysis. Value Health 2019;22:56.

51. Treister N, Nieder M, Baggott C, Olson E, Chen L, Dang H, et al. Caphosol for prevention of oral mucositis in pediatric myeloablative haematopoietic cell transplantation. Br J Cancer 2016;116:121.

52. Murdock JL, Reeves DJ. Chemotherapy-induced oral mucositis management: A retrospective analysis of MuGard, Caphosol, and standard supportive care measures. J Oncol Pharm Pract. 2019;26(3):521-528.

53. Svanberg A, Öhrn K, Birgegård G. Caphosol ${ }^{\circledR}$ mouthwash gives no additional protection against oral mucositis compared to cryotherapy alone in stem cell transplantation. A pilot study. Eur J Oncol Nurs. 2015; 19(1):50-53.

54. Wong KH, Kuciejewska A, Sharabiani MTA, Ng-Cheng-Hin B, Hoy S, Hurley T, et al. A randomised controlled trial of Caphosol mouthwash in management of radiation-induced mucositis in head and neck cancer. Radiother Oncol. 2017;122(2):207-211.

55. Yarom N, Hovan A, Bossi P, Ariyawardana A, Jensen SB, Gobbo M, et al. Systematic review of natural and miscellaneous agents for the management of oral mucositis in cancer patients and clinical practice guidelines-part 1: vitamins, minerals, and nutritional supplements. Support Care Cancer. 2019;27(10):3997-4010.

56. Rambod M, Pasyar N, Ramzi M. The effect of zinc sulfate on prevention, incidence, and severity of mucositis in leukemia patients undergoing chemotherapy. Eur J Oncol Nurs. 2018;33:14-21.

57. Tian X, Liu X-L, Pi Y-P, Chen H, Chen W-Q. Oral zinc sulfate for prevention and treatment of chemotherapy-induced oral mucositis: a meta-analysis of five randomized controlled trials. Front Oncol 2018;8:484.

58. Cruzat V, Macedo Rogero M, Noel Keane K, Curi R, Newsholme P. Glutamine: Metabolism and immune function, supplementation and clinical translation. Nutrients. 2018;10(11):1564.

59. Sayles C, Hickerson SC, Bhat RR, Hall J, Garey KW, Trivedi MV. Oral glutamine in preventing treatment-related mucositis in adult patients with cancer: a systematic review. Nutr Clin Pract 2016;31(2):171-179.

60. Pathak S, Soni TP, Sharma LM, Patni N, Gupta AK. A randomized controlled trial to evaluate the role and efficacy of oral glutamine in the treatment of chemo-radiotherapy-induced oral mucositis and dysphagia in patients with oropharynx and larynx carcinoma. Cureus. 2019; 11 (6): e4855.

61. Manzi ND, Silveira R, dos Reis PED. Prophylaxis for mucositis induced by ambulatory chemotherapy: systematic review. J Adv Nurs 2016;72(4):735-746.

62. Oberoi S, Zamperlini-Netto G, Beyene J, Treister NS, Sung L. Effect of prophylactic low level laser therapy on oral mucositis: a systematic review and meta-analysis. PLoS one. 2014;9(9):e107418.

63. Ferreira B, da Motta Silveira FM, de Orange FA. Low-level laser therapy prevents severe oral mucositis in patients submitted to hematopoietic stem cell transplantation: a randomized clinical trial. Support Care Cancer. 2016;24(3):10351042.

64. Silva GBL, Sacono NT, Othon-Leite AF, Mendonça EF, Arantes AM, Bariani C, et al. Effect of low-level laser therapy on inflammatory mediator release during chemotherapy-induced oral mucositis: a randomized preliminary study. Lasers Med Sci 2015;30(1):117-126.

65. Zadik Y, Arany PR, Fregnani ER, Bossi P, Antunes HS, Bensadoun R-J, et al. Systematic review of photobiomodulation for the management of oral mucositis in cancer patients and clinical practice guidelines. Support Care Cancer. 2019;27(10):3969-3983.

66. Gholizadeh N, Sheykhbahaei N, Sadrzadeh-Afshar M-S. New treatment approaches of oral mucositis: a review of literature. Adv Hum Biol 2016;6(2):66.

67. Park S-H, Han SH. Effect of oral cryotherapy for reducing oral mucositis in hematopoietic stem cell transplantation: a systematic review and meta-analysis. Korean J. Adult Nurs. 2018;30(4):362-375. 
68. Correa MEP, Cheng KKF, Chiang K, Kandwal A, Loprinzi CL, Mori T, et al. Systematic review of oral cryotherapy for the management of oral mucositis in cancer patients and clinical practice guidelines. Support Care Cancer. 2019;28 (5): $2449-2456$.

69. Samdariya S, Lewis S, Kauser H, Ahmed I, Kumar D. A randomized controlled trial evaluating the role of honey in reducing pain due to radiation induced mucositis in head and neck cancer patients. Indian J Palliat 2015;21(3):268-273.

70. Cho HK, Jeong YM, Lee HS, Lee YJ, Hwang SH. Effects of honey on oral mucositis in patients with head and neck Cancer: A meta-analysis. The Laryngoscope. 2015;125(9):2085-2092.

71. Xu JL, Xia R, Sun ZH, Sun L, Min X, Liu C, et al. Effects of honey use on the management of radio/chemotherapyinduced mucositis: a meta-analysis of randomized controlled trials. Int J Oral Maxillofac Surg. 2016;45(12):1618-1625.

72. Nagi R, Patil DJ, Rakesh N, Jain S, Sahu S. Natural agents in the management of oral mucositis in cancer patientssystematic review. J Oral Biol Craniofac Res 2018;8(3):245-254.

73. Raeessi MA, Raeessi N, Panahi Y, Gharaie H, Davoudi SM, Saadat A, et al. "Coffee plus Honey" versus "topical steroid" in the treatment of chemotherapy-induced oral mucositis: a randomised controlled trial. BMC Complement Altern Med 2014;14(1):293.

74. Khanjani Pour-Fard-Pachekenari A, Rahmani A, Ghahramanian A, Asghari Jafarabadi M, Onyeka TC, Davoodi A. The effect of an oral care protocol and honey mouthwash on mucositis in acute myeloid leukemia patients undergoing chemotherapy: a single-blind clinical trial. Clin Oral Investig 2019;23(4):1811-1821.

75. Przybylek I, Karpinski TM. Antibacterial properties of propolis. Molecules. 2019;24(11):2047.

76. Ferreira JM, Fernandes-Silva CC, Salatino A, Negri G, Message D. New propolis type from north-east Brazil: chemical composition, antioxidant activity and botanical origin. J Sci Food Agric. 2017;97(11):3552-3558.

77. Kasiotis KM, Anastasiadou P, Papadopoulos A, Machera K. Revisiting Greek Propolis: Chromatographic Analysis and Antioxidant Activity Study. Plos One. 2017;12(1):e0170077.

78. Anjum S, Ullah A, Khan K, Attaullah M, Khan H, Ali H, et al. Composition and functional properties of propolis (bee glue): A review. Saudi J Biol Sci 2018;26(7):1695-1703.

79. Bolouri AJ, Pakfetrat A, Tonkaboni A, Aledavood SA, Najafi MF, Delavarian Z, et al. Preventing and therapeutic effect of propolis in radiotherapy induced mucositis of head and neck cancers: a triple-blind, randomized, placebo-controlled trial. Iran J Cancer Prev 2015;8(5):e4019.

80. Piredda M, Facchinetti G, Biagioli V, Giannarelli D, Armento G, Tonini G, et al. Propolis in the prevention of oral mucositis in breast cancer patients receiving adjuvant chemotherapy: A pilot randomised controlled trial. Eur J Cancer 2017;26(6):1-8

81. Chaitanya NC, Muthukrishnan A, Babu DBG, Kumari CS, Lakshmi MA, Palat G, et al. Role of vitamin E and vitamin A in oral mucositis induced by cancer chemo/radiotherapy- a meta-analysis. J Clin Diagn Res 2017;11(5):4.

82. Khurana A, Tekula S, Saifi MA, Venkatesh P, Godugu C. Therapeutic applications of selenium nanoparticles. Biomedicine \& Pharmacotherapy. 2019;111:802-812.

83. Ameri A, Abbasinazari M, Fazeli A, Sarafzadeh F, Mahboubi A. The effect of oral selenium on radiotherapy induced mucositis in patients with head and neck cancer: a pilot double-blind study. JKMU 2016;23(1):12-20.

84. Radha MH, Laxmipriya NP. Evaluation of biological properties and clinical effectiveness of Aloe vera: A systematic review. J Tradit Complement Med 2015;5(1):21-26.

85. Aghamohamamdi A, Hosseinimehr SJ. Natural products for management of oral mucositis induced by radiotherapy and chemotherapy. Integr Cancer Ther 2016;15(1):60-68.

86. Chen H, Pu J, Liu D, Yu W, Shao Y, Yang G, et al. Anti-inflammatory and antinociceptive properties of flavonoids from the fruits of black mulberry (Morus nigra L.). Plos One. 2016;11(4):e0153080.

87. Li Y, Bao T, Chen W. Comparison of the protective effect of black and white mulberry against ethyl carbamate-induced cytotoxicity and oxidative damage. Food Chem 2018;243:65-73.

88. Demir Doğan M, Can G, Meral R. Effectiveness of black mulberry molasses in prevention of radiotherapy-induced oral mucositis: a randomized controlled study in head and neck cancer patients. J Altern Complement Med. 2017;23(12):971979.

89. Harman M, Ovayolu N, Ovayolu O. The effect of three different solutions on preventing oral mucositis in cancer patients undergoing stem cell transplantation: a non-randomized controlled trial: A Turkish study-non-randomised trial. J Pak Med Assoc. 2019;69(6):811-816.

90. Leppla L, De Geest S, Fierz K, Deschler-Baier B, Koller A. An oral care self-management support protocol (OrCaSS) to reduce oral mucositis in hospitalized patients with acute myeloid leukemia and allogeneic hematopoietic stem cell transplantation: a randomized controlled pilot study. Support Care Cancer. 2016;24(2), 773-782.

91. Carvalho CG, Medeiros-Filho JB, Ferreira MC. Guide for health professionals addressing oral care for individuals in oncological treatment based on scientific evidence. Support Care Cancer. 2018;26(8):2651-2661.

92. Lopes LD, Rodrigues AB, Brasil DRM, Moreira MMC, Amaral JG, Oliveira PPD. Prevention and treatment of mucositis at an oncology outpatient clinic: a collective construction. Texto \& Contexto - Enfermagem. 2016;25(1).

93. Avci S, Sari HY. Effect of an evidence-based nursing intervention on the diagnosis of oral mucositis in the pediatric stem cell transplant unit. Asia Pac J Oncol Nurs. 2019;6(3), 292-299.

94. Kanagalingam J, Wahid MIA, Lin J-C, Cupino NA, Liu E, Kang J-H, et al. Patient and oncologist perceptions regarding symptoms and impact on quality-of-life of oral mucositis in cancer treatment: results from the Awareness Drives Oral Mucositis PercepTion (ADOPT) study. Support Care Cancer. 2018;26(7):2191-2200. 